\title{
BIDIRECTIONAL SHIFTS IN COLONY QUEEN NUMBER IN A SOCIALLY POLYMORPHIC ANT POPULATION
}

\author{
Jessica Purcell ${ }^{1,2}$ and Michel Chapuisat ${ }^{1}$ \\ ${ }^{1}$ Department of Ecology and Evolution, University of Lausanne, Bâtiment Biophore, Quartier UNIL-Sorge, 1015 Lausanne, \\ Switzerland \\ ${ }^{2}$ E-mail: Jessica.Purcel/@unil.ch
}

Received April 9, 2012

Accepted October 8, 2012

Data Archived: doi 10.5061/dryad.6qd10

\begin{abstract}
The breeding system of social organisms affects many important aspects of social life. Some species vary greatly in the number of breeders per group, but the mechanisms and selective pressures contributing to the maintenance of this polymorphism in social structure remain poorly understood. Here, we take advantage of a genetic dataset that spans 15 years to investigate the dynamics of colony queen number within a socially polymorphic ant species. Our study population of Formica selysi has singleand multiple-queen colonies. We found that the social structure of this species is somewhat flexible: on average, each year $3.2 \%$ of the single-queen colonies became polygynous, and conversely $1.4 \%$ of the multiple-queen colonies became monogynous. The annualized queen replacement rates were $10.3 \%$ and $11.9 \%$ for single- and multiple-queen colonies, respectively. New queens were often but not always related to previous colony members. At the population level, the social polymorphism appeared stable. There was no genetic differentiation between single- and multiple-queen colonies at eight microsatellite loci, suggesting ongoing gene flow between social forms. Overall, the regular and bidirectional changes in queen number indicate that social structure is a labile trait in $\mathrm{F}$. selysi, with neither form being favored within a time-frame of 15 years.
\end{abstract}

KEY WORDS: Formicinae, hymenoptera, monogyny, parentage analysis, phenotypic plasticity, polygyny, social evolution.

Social organisms vary in their breeding system, which affects many socially important traits, including group genetic diversity and nestmate relatedness (Balloux et al. 1998; Ross 2001; Sommer et al. 2002; Ost et al. 2008; Bourke 2011). Groups with increasing numbers of breeders tend to have lower levels of relatedness than those with few breeders, although kin relationships between the breeders and reproductive skew may contribute to preventing the erosion of relatedness (e.g., Ross 1993; Heinze et al. 1995; Chapuisat and Keller 1999). The degree of intragroup relatedness, in turn, has many implications for the ontogeny of the social group, as well as for the structure and degree of cooperation and conflict (e.g., Crozier and Pamilo 1996). Ross (2001) pointed out that investigating the population genetic consequences of differ- ent breeding systems can help to address fundamental questions about the origin of sociality and the nature of selection in hierarchically structured populations. He also cautioned that breeding systems may change through time in a population, which calls for studies on temporal variation in breeding systems.

Many species of social Hymenoptera form colonies headed by one singly mated female, leading to high levels of relatedness among colony members (reviewed by Keller 1995b; Heinze and Keller 2000; Ross 2001). Monogamy has been shown to be the ancestral state in which eusociality emerged in ants, bees, and wasps (Boomsma 2007; Hughes et al. 2008a). However, breeding systems that lower intracolony relatedness have evolved multiple times, particularly in ants (e.g., Hughes et al. 2008b). This begs 
the question of what ecological conditions and selective pressures favor social structures with multiple breeders. This question can be addressed by investigating natural variation in social systems (Purcell 2011), particularly intraspecific variation in species that exhibit distinct social structures in the same population (e.g., Chapuisat et al. 2004; Seppä et al. 2004). Some species vary in the number of males with which the queen mates ( = polyandry). Other species vary in the number of queens reproducing in a colony, with some colonies headed by a single queen $(=$ monogynous) and other colonies headed by two or more queens ( = polygynous; e.g., Crozier and Pamilo 1996; Hughes et al. 2008b).

There are several evolutionary hypotheses to explain the presence of multiple breeders in the same colony. First, increasing the genetic diversity of a group often enables members to better defend against pathogens (Keller 1995a; Schmid-Hempel and Crozier 1999; Reber et al. 2008). Another nonmutually exclusive hypothesis proposes that polygyny is favored when nest sites are rare and dispersal risky, for example due to high intraspecific competition, unfavorable or saturated environmental conditions, or predation (e.g., Hölldobler and Wilson 1977; Keller 1995b; Pedersen and Boomsma 1999). In line with the latter hypothesis, queens from monogynous and polygynous species generally differ in their dispersal ability and mode of colony founding (e.g., Keller and Passera 1989). Queens from monogynous species are typically better dispersers and can found new colonies independently. In contrast, queens from polygynous species often tend to stay in their natal nest or establish new nests by budding (e.g., Nonacs 1988; Chapuisat et al. 1997; Chapuisat and Keller 1999; Kautz et al. 2009).

Another unanswered question about breeding system variation in social insects is the extent to which the system is controlled by genetic factors versus environmental factors generating phenotypic plasticity. At one extreme, the red fire ant Solenopsis invicta exhibits differences in queen number that appear to be genetically controlled (Ross and Keller 1998; Krieger and Ross 2002). At the other extreme, ant colonies may be able to flexibly adjust queen number to best match the environment in which they find themselves (suggested by Herbers 1986, 1993; Ingram 2002). We do not yet know where most polymorphic species lie along this continuum.

Molecular methods are often used to get a snapshot of the state of a population, which potentially allows us to infer some aspects of its past dynamics. Several studies have used this approach to investigate the genetic structure and gene flow in socially polymorphic ant populations. In some species, including Formica selysi, F. podzolica, F. exsecta, and F. fusca there was no genetic differentiation between monogynous and polygynous colonies at the investigated microsatellite loci, suggesting persistent gene flow between social forms (Chapuisat et al. 2004; DeHeer and Herbers 2004; Seppä et al. 2004; Bargum et al. 2007).
This pattern could emerge if social structure is a phenotypically plastic trait that varies according to ecological conditions or ontogeny of the colony (Bargum et al. 2007; Field et al. 2010; Reber et al. 2010; Meunier et al. 2011). Alternatively, some polymorphic genetic elements unlinked to the investigated microsatellite markers may influence social structure (Chapuisat et al. 2004; Meunier and Chapuisat 2009; Purcell and Chapuisat 2012).

Several other species, including $F$. cinerea, F. truncorum, $S$. invicta, and Tetramorium moravicum, showed restricted gene flow between monogynous and polygynous colonies or populations (Shoemaker and Ross 1996; Goropashnaya et al. 2001; Gyllenstrand et al. 2005; Schlick-Steiner et al. 2007). In these cases, the authors suggest that the different forms may be on a course toward increasing differentiation and eventual speciation. Further research is required to determine what mechanisms underlie each type of population structure. In particular, investigations of changes in social structure over time are needed to learn about the long-term stability of this polymorphism in populations and the lability of the trait within colonies.

Very few socially polymorphic ant populations have been monitored over long time periods. A study of three Myrmica species found that the social polymorphism persisted in populations for 10 to 15 years (Elmes 1987; Elmes and Petal 1990). However, they used nest excavation to determine queen number; this destructive sampling precludes the possibility of following the dynamics of individual colonies, and may itself affect the population structure. Using molecular markers to monitor breeding systems would enable the simultaneous investigation of colonyand population-level dynamics. To our knowledge, the long-term dynamics of queens in individual colonies has not been investigated in socially polymorphic ant species.

Such monitoring of queen dynamics within colonies is of interest, as interspecific comparisons indicate that monogyny and polygyny are generally associated with distinct queen longevity and rates of queen replacement (Bourke and Franks 1995; Keller and Genoud 1997). Queens from monogynous species have very long life spans, with means as high as 20 years in some species (Keller 1998). Queen replacement is rare, and generally the colony life span equals the queen life span, although exceptions do occur (Heinze and Keller 2000). In contrast, the queens of polygynous species tend to have short life spans (Keller and Genoud 1997) and queen replacement, usually by related daughter queens, is common (e.g., Crozier and Pamilo 1996; Evans 1996; Chapuisat and Keller 1999). The polygynous colonies can thus persist over many generations. Overall, there is a sharp contrast in colony ontogeny and life history between monogynous and polygynous species (e.g., Bourke and Franks 1995). It is less clear whether this sharp contrast is also present between monogynous and polygynous colonies within socially polymorphic species (Chapuisat et al. 2004; Rosset and Chapuisat 2007). 
In our study species Formica selysi, we observe continuous variation in queen number within a single population, with a mix of monogynous colonies and polygynous colonies (Chapuisat et al. 2004; up to 15 queens observed in single polygynous colonies, Purcell and Chapuisat, unpubl. data). Data on this species suggest that it shares characteristics with both facultatively polygynous and socially polymorphic ant species. On the one hand, queens of both social origins were capable of founding nests alone or in associations in the laboratory (Reber et al. 2010), and workers from each social form were equally likely to accept newly mated nestmate queens and to reject newly mated foreign queens (Meunier et al. 2011). These experimental results, in combination with the continuous variation in queen number and the lack of genetic differentiation at nine microsatellite loci (Chapuisat et al. 2004), suggest that this species may be facultatively polygynous. On the other hand, the two forms differ in many ecologically and socially relevant traits. Monogynous workers and gynes were significantly larger than polygynous ones, although males from each social form did not differ in size (Schwander et al. 2005; Rosset and Chapuisat 2007). Polygynous colonies had about ten times more workers and tended to persist about three times longer than monogynous colonies; they also tended to occur in areas of higher colony density (Rosset and Chapuisat 2007). In experiments where we cross-fostered eggs, the size of gynes reflected their genetic origin rather than the background of their caregivers (Meunier and Chapuisat 2009), as did the development time and growth rate of worker brood (Purcell and Chapuisat 2012). These clear differences between social forms indicate that F. selysi exhibits some characteristics that are more consistent with socially polymorphic species, and suggest that there may be some as-yet undetected genes that differ between the two social forms. Overall, social structure covaries with many traits, but depending on the trait, the basis of this association seems to be genetic (e.g., body size) or ontogenetic (e.g., colony founding or acceptance of new queens).

In the current study, we take advantage of a genetic dataset that spans 15 years to investigate the temporal dynamics of queen number at both the colony and the population level. We address two main questions. First, we ask to what extent the social structure of individual colonies remains stable through time by quantifying shifts from one social form to the other, genetic turnover, queen replacement events and colony extinction. Second, we investigate whether the average relatedness and proportion of each social form change over time at the population level. Answering these questions will provide insights into the stability of the polymorphism, both within colonies and across the population. This, in turn, will aid in the ongoing search to identify selective forces that are important in driving the evolution and maintenance of alternative social forms.

\section{Materials and Methods}

The ant Formica selysi occurs in valleys throughout the Alps and the Pyrenees in Europe. Our study population is adjacent to the Rhône river between Sierre and Susten in Valais, Switzerland (7’36’30’'E, 46 18’30’N, altitude $565 \mathrm{~m}$ ). The study site encompasses a flood plain and steppe habitat in an area of approximately $1500 \times 400 \mathrm{~m}$ (Supplementary Materials, Fig. S2). The field site is divided into spatial patches of similar size. Patches are separated in space $(50-400 \mathrm{~m})$ and/or by ecological transitions, such as a transition from open steppe to closed forested habitat. The ecology, social structure, social behavior, sex ratio, and social immunity of this species have been studied in detail (e.g., Chapuisat et al. 2004; Rosset and Chapuisat 2006, 2007; Reber et al. 2008, 2010, 2011; Meunier and Chapuisat 2009; Meunier et al. 2010, 2011; Purcell et al. 2012; Purcell and Chapuisat 2012).

\section{COLONY MONITORING}

In 2000 to 2001, we began to individually mark colonies for longterm monitoring. Additional colonies were marked in 2005 to 2007 and 2009 to 2010. We placed a flat stone over each colony, recorded its geographic position with a Global Positioning System, and marked it with a radio-frequency identification tag buried next to the nest entrance to ensure that identification would be possible for different observers and across different years. Each year, we inspected all marked colonies at least once during the sexual production period in June. Most colonies were checked two to ten more times annually during the activity period of ants, between March and October. Colonies were considered to be extinct if there were no tunnel entrances under or near the stones, no workers, and/or other species under the stones. Due to the high frequency of inspections, we could generally distinguish between events of colony extinction followed by nest recolonization and events of complete queen replacement in live colonies. In particular, cases of colony extinction and recolonization by mated queens after the nuptial flight are easy to detect, because the flights occur only in late June-early July and the build-up of a new workforce in incipient colonies takes several years. Quick recolonization by queens and workers budding from nearby polygynous colonies would be more difficult to detect, and might in a few cases be mistaken for complete queen replacement without colony extinction. However, the lack of isolation-by-distance in the polygynous social form suggests that dispersal by budding is not frequent in our study population (Chapuisat et al. 2004; Supplementary Materials, part IV).

\section{SAMPLING: INTRACOLONY DYNAMICS}

To investigate whether colony social structure remained stable through time, we genotyped workers from each of 121 marked 
nests repeatedly across multiple years, between 2000 and 2010 . Eleven of these nests were sampled before and after an extinction/recolonization event, whereas the others were occupied continuously. In addition to the 121 nests that we resampled, we monitored 27 monogynous colonies and 15 polygynous colonies that went extinct without having been resampled. For detailed information on the sampling scheme, see Supplementary Materials, part I.

Our total observation effort for resampled colonies, excluding extinction/recolonization events, was 314 and 284 colony $\times$ years for monogynous and polygynous colonies, respectively. The number of years intervening sampling events was distributed as follows: we resampled 50 times after 1 year, seven times after 2 years, 36 times after 3 years, 85 times after 4 years, six times after 5 years, one time after 6 years, four times after 8 years, and twice after 9 years. In total, we resampled colonies 191 times, with an average interval of 3.13 years between sampling events. We calculated the approximate annualized rates of social structure shift and queen replacement by dividing the number of observations by the observation effort. Because the colonies were not sampled each year, our annualized rates are likely to be conservative estimates.

We calculated the annual probability of colony extinction by dividing the number of extinction events by the number of years that colonies of each social form were monitored. We then estimated colony longevity as the inverse of this annual colony extinction rate (Pamilo 1991b).

\section{SAMPLING: INTERCOLONY DYNAMICS}

To determine whether the social polymorphism has remained stable through time at the population level, we calculated the average intracolony relatedness and $95 \%$ confidence intervals for each year, over all colonies sampled in that year. In complement, we examined whether the proportion of monogynous colonies varied over years.

We performed these tests using genetic data collected on 257 F. selysi colonies sampled over the past 15 years. In 1996, 10 adult workers were sampled from each of 25 colonies (Chapuisat et al. 2004) and were genotyped at three microsatellite loci as described in Chapuisat (1996). In the 2000 to 2001 sampling, we collected at least eight workers and up to 16 brood from each of 114 colonies and genotyped each individual at up to nine polymorphic microsatellite loci (Chapuisat et al. 2004). From 2002 onward, we genotyped workers at eight polymorphic microsatellite loci. In 2002, we genotyped eight workers from newly marked colonies $(N=8)$. In 2005 to 2007, we genotyped at least five workers from resampled colonies $(N=88)$ and at least eight workers from newly marked colonies $(N=68)$. In 2009 to 2010, we genotyped eight workers from previously sampled colonies $(N=79)$ and from previously unsampled colonies $(N=42)$.

\section{ANALYSIS OF COLONY SOCIAL STRUCTURE}

We determined colony social structure and social structure shifts conservatively, by excluding cases where a polygynous social structure or a change in social structure was only supported by differences in a single individual or at a single locus. Indeed, such cases might be due to the accidental collection of vagrant workers or from genotyping errors. These putative sources of error were rare. For about $5 \%$ of the colonies classified as monogynous, one individual belonged to a different sibship group than all the others in 1 year, but this rare sibship group was not sampled again later on, suggesting a vagrant worker. We also occasionally found that a worker differed from the others at only one allele, suggesting a genotyping error. This occurred at a mean rate of about $1 \%$ per locus among workers belonging to monogynous colonies, which is in line with average error rates of $0.5 \%$ to $1 \%$ that have been estimated for microsatellite loci in other laboratories (Pompanon et al. 2005).

We used three complementary approaches to assess the social structure of each colony (monogynous vs. polygynous) and the incidence of multiple matings by queens. First, we used the computer program Colony (Wang 2004; Wang and Santure 2009) to distinguish between colonies headed by one singly-mated queen, a single queen mated with two males, or multiple queens. This program uses a maximum likelihood approach to assign individuals to full and half-sib groups on the basis of their microsatellite genotypes. Colonies containing only full sibs were determined to be monogynous, colonies containing full and half sibs were assumed to be monogynous with a multiply-mated queen, and colonies with more complicated membership at a single point in time were determined to be polygynous. We looked at the sibship assignments in each colony both within years and across years to estimate queen replacement and shifts in queen number over time.

We also used the computer program Coancestry (Wang 2011) to calculate the relatedness among nestmates within each colony (Queller and Goodnight 1989). We plotted the results for colonies sampled in 2009 to 2010 (Fig. S3) and found a bimodal distribution of relatedness values similar to those reported for colonies sampled in 2000 to 2001 (Chapuisat et al. 2004). All colonies in the peak with smaller relatedness values (average $\pm \mathrm{SE}=0.22$ \pm 0.02 ) were assumed to be polygynous, while those in the peak with larger relatedness values were assumed to be monogynous (average $\pm \mathrm{SE}=0.71 \pm 0.02$ ). We further inspected the genotype arrays from colonies with intermediate relatedness values to assign their social structure.

In 89\% of the cases COLONY and COANCESTRY returned identical results for colony social structure. To further verify the social structure and resolve the few cases were the two approaches gave conflicting results, we developed a third analysis method based on a simple algorithm to calculate the minimum number of 
parents required to produce the offspring genotypes (see Supplementary Materials, part II for methodological details).

Overall, we found that COANCESTRY, our "parent number" algorithm and the inspection of the genotype arrays resulted in very similar assessments of colony social structure. In contrast, COLONY tended to overestimate the number of parents in each colony relative to our other approaches, probably because it was more sensitive to genotyping errors. We based our subsequent analyses of colony structure variation through time on the consensus results from COANCESTRY, our algorithm and an inspection of the genotype arrays. In complement, pedigree reconstruction from COLONY permitted us to better identify queen replacement events and shifts in social structure.

\section{ANALYSIS OF INTRACOLONY DYNAMICS}

We calculated the effective queen number $(f)$ in polygynous colonies as:

$$
f=3 /(4 r),
$$

where $r$ is the relatedness among workers. By definition, effective queen number reflects a hypothetical situation where queens are unrelated, singly mated to unrelated males, and contribute equally to reproduction. In polygynous colonies, queens often stay in their natal nests, and therefore tend to be related (Crozier and Pamilo 1996). If old queens are replaced by new queens originating from the same colony in way similar to workers, the queens will be as related as the workers. Assuming a stable number of queens, the effective number of related queens $\left(f_{r}\right)$ becomes:

$$
f_{\mathrm{r}}=(3-r) /(3 r)
$$

(e.g., Pamilo 1991a).

For monogynous colonies, we calculated the effective mate number $\left(m_{\mathrm{e}}\right)$ as:

$$
m_{\mathrm{e}}=2 /\left(4 r_{\mathrm{b}}-1\right)
$$

(e.g., Boomsma and Ratnieks 1996; Chapuisat 1998), where $r_{\mathrm{b}}$ is the mean relatedness within the brood of a single queen.

Following Evans (1996), we also calculated the effective genetic turnover $\left(Q_{\mathrm{e}}\right)$ based on the relatedness among nestmates sampled in the first year $\left(r_{11}\right)$, in the second year $\left(r_{22}\right)$, and between nestmates sampled in different years $\left(r_{12}\right)$ using the formula:

$$
Q_{\mathrm{e}}=1-\left[2 r_{12} /\left(r_{11}+r_{22}\right)\right]
$$

(e.g., Evans 1996; Chapuisat et al. 2004).

This formula estimates the average genetic turnover between samples. $Q_{\mathrm{e}}$ mostly reflects the replacement of reproducers (queens and mates) by individuals that are less related to the workers, which decreases the between-sample estimate of relatedness. In monogynous colonies, high values of $Q_{\mathrm{e}}$, indicating genetic turnover, were consistent with queen replacement events observed using pedigree analysis in COLONY. In polygynous colonies, high genetic turnover also indicates queen replacement by new queens that may be both less related themselves and may have mated with unrelated males (Chapuisat et al. 2004; Meunier et al. 2011). The higher genetic diversity in polygynous colonies makes it more difficult to assess actual queen replacement events using pedigree analysis. We can, however, estimate the average rate of effective queen replacement $(\tau)$; assuming that queens reproduce equally and mate with unrelated males, we calculated $\tau$ as:

$$
\tau=1-\left[r_{12} /\left(r_{11}+r_{22}-r_{12}\right)\right]
$$

(Pedersen and Boomsma 1999).

This equation allows for changes in the number of mothers among cohorts, but will result in a lower $\tau$ value if old queens are replaced by related queens than if they are replaced by nonrelatives.

To complement these calculations, we additionally examined intracolony relatedness levels across sampling events (Table 1; Fig. S4). In monogynous colonies, we could detect cases of queen replacement and infer if the new queens were related to the old ones by examining the relatedness of workers from the first sample to workers from the second sample of the same colonies. This method was not powerful in polygynous colonies, where the ability to detect queen replacement and assess the relatedness of a new queen depends on the number and relatedness of existing queens. Nevertheless, we could still detect some cases of changes in effective queen number and queen replacement in polygynous colonies using this method in combination with equations 4 and 5 . In all cases, confidence intervals were measured using the bias corrected and accelerated $\left(\mathrm{BC}_{\mathrm{a}}\right)$ method included in the boot package in R 2.10 (R Core Development Team 2009).

\section{Results \\ WITHIN-COLONY DYNAMICS}

Overall, we found that colonies occasionally shifted from one social structure to another over the course of our 10-year monitoring period. These shifts were bidirectional (Fig. 1, Table 1). Queen replacement events were also observed in both monogynous and polygynous colonies. Monogynous colonies went extinct about twice as often as polygynous ones (Fig. 1), and a few empty nest sites were recolonized by each social form.

\section{Monogynous colonies}

Monogynous colonies became polygynous at an annualized rate of $3.2 \%$ (Table 1). In four out of the six cases wherein the 
Table 1. Summary of the dynamics of colonies through time, as inferred from the repeated sampling and genotyping of workers from the same colonies across years. The initial number of colonies was 59 and 51 for monogynous and polygynous colonies, respectively. $Q_{e}$ is the effective genetic turnover. $95 \%$ confidence intervals are given in square brackets; \pm standard errors are shown for relatedness calculations. $\boldsymbol{N}$ indicates the number of colonies in each category.

\begin{tabular}{lll}
\hline & Monogynous Colonies & Polygynous Colonies \\
\hline Average $Q_{\mathrm{e}}$ (Eq. 4) for all resampled colonies & $0.25[0.17 ; 0.32]$ & $0.44[0.16 ; 0.72]$ \\
Social structure shift & & \\
Original queen kept & $N=6$ & $N=2$ \\
Average relatedness among workers in first sample/across samples/second & $0.77 / 0.46 / 0.47$ & $0.33 / 0.42 / 0.60$ \\
$\quad$ sample & $\pm 0.04 / 0.12 / 0.09$ & $\pm 0.14 / 0.10 / 0.09$ \\
$Q_{\mathrm{e}}$ & $0.30[-0.10 ; 0.69]$ & $0.02[-0.05 ; 0.08]$ \\
Original queen replaced & $N=4$ & $N=2$ \\
Average relatedness among workers in first sample/across samples/second & $0.71 /-0.1 / 0.29$ & $-0.01 /-0.08 / 0.71$ \\
$\quad$ sample & $\pm 0.09 / 0.03 / 0.11$ & $\pm 0.04 / 0.03 / 0.06$ \\
$Q_{\mathrm{e}}$ & $1.21[1.15 ; 1.27]$ & $1.21[1.13 ; 1.30]$ \\
Same social structure & & \\
Original queen(s) kept & $N=31$ & $N=45$ \\
Average relatedness among workers in first sample/across samples/second & $0.71 / 0.67 / 0.71$ & $0.13 / 0.09 / 0.16$ \\
$\quad$ sample & $\pm 0.02 / 0.02 / 0.02$ & $\pm 0.02 / 0.02 / 0.02$ \\
$Q_{\mathrm{e}}$ & $0.06[0.03 ; 0.08]$ & $0.37[0.16 ; 0.72]$ \\
Original queen(s) replaced (complete turnover) & $N=18$ & $N=2$ \\
Average relatedness among workers in first sample/across samples/second & $0.74 / 0.19 / 0.72$ & $0.18 /-0.16 / 0.04$ \\
$\quad$ sample & $\pm 0.02 / 0.06 / 0.03$ & $\pm 0.01 / 0.09 / 0.04$ \\
$Q_{\mathrm{e}}$ & $0.75[0.59 ; 0.91]$ & $2.32[1.06 ; 3.58]$ \\
\hline
\end{tabular}

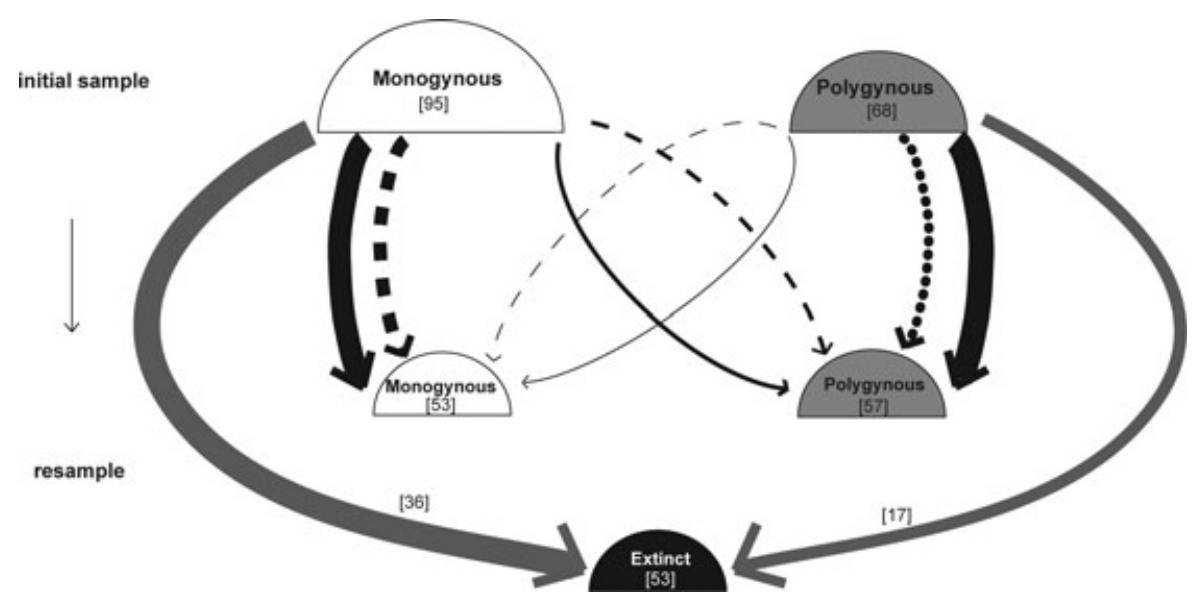

Figure 1. Schematic diagram showing the within colony dynamics observed in colonies genotyped more than once or that went extinct during our study period. The size of each mound and the thickness of each arrow represent the proportion of colonies that fit into each category. Solid black lines represent colonies that kept the same queen(s) across sampling periods, dashed lines represent instances of queen replacement, and the dotted line represents significant changes in queen number within polygynous groups. Of the 13 polygynous colonies that changed in queen number, two exhibited complete queen replacement. Square brackets indicate sample sizes. Additional details are presented in Table 1.

original queen remained present in the colony, the offspring of newly adopted queens were closely related to the original workers, and the relatedness values among workers sampled before and after the social structure shift were fully consistent with the newly adopted queen being the daughter of the original queen (average intracolony relatedness \pm standard error before the shift: $r=0.79 \pm 0.04$, after the shift: $r=0.56 \pm 0.05$ and between the two samples: $r=0.64 \pm 0.05$ ). In six other colonies, two that kept the original queen and four that replaced it, the relatedness measures indicate that the colonies gained unrelated queens (average relatedness before shift: $r=0.72 \pm 0.06$, after shift: $r=0.29 \pm 0.09$ and between the two samples $r=-0.04 \pm 0.05$ ). 
These social structure shifts were confirmed by direct pedigree inspection and with our algorithm inferring the number of parents.

In as many as $18(31 \%)$ of the monogynous colonies, the original queen was replaced by a single new queen (queen replacement actually occurred twice in one of these colonies, and once in a colony that later shifted to polygyny). Based on these observations, the annualized rate of queen replacement was about $6.4 \%$ (Table 1). In 12 of these colonies, the new queen was likely to be a relative of the original queen (average relatedness $\pm \mathrm{SE}$ before shift: $r=0.70 \pm 0.02$, after shift: $r=0.71 \pm 0.04$ and between the two samples $r=0.42 \pm 0.06$ ), whereas the new queen appeared to be a nonrelative in the six remaining colonies (average relatedness before shift: $r=0.69 \pm 0.05$, after shift: $r=0.74 \pm 0.05$ and between the two samples $r=-0.08 \pm 0.07$; see also Fig. S4).

The effective genetic turnover $\left(Q_{\mathrm{e}} \pm \mathrm{SE}\right)$ detected in monogynous colonies was $0.25 \pm 0.04$ across all resampling events. This turnover reflects queen replacement and social structure shift through queen adoption. Looking at resampling intervals of different lengths, we found that colonies resampled after 1 to 2 years $(N=31)$ had a similar genetic turnover rate $\left(Q_{\mathrm{e}}=0.21 \pm 0.06\right)$ as those resampled after 3 to 4 years $\left(N=69 ; Q_{\mathrm{e}}=0.25 \pm 0.05\right)$. The average genetic turnover in colonies resampled after 5 years or more was higher $\left(N=4 ; Q_{\mathrm{e}}=0.81 \pm 0.26\right)$, indicating that over the years, a large proportion of monogynous colonies experienced queen replacement by relatively unrelated queens mated to unrelated males. Across all sampling periods, the effective queen replacement rate $(\tau)$ was 0.33 , which translates to an annualized rate of $10.3 \%$. This value is not significantly higher than the queen replacement rate of $6.4 \%$ estimated through pedigree analysis (Fisher's exact test: $P=0.11$ ).

During our study period, 36 of 128 marked monogynous colonies $(28 \%)$ went extinct. In total, this translates to an annual extinction rate of $5.7 \%$. Nine abandoned nest sites from monogynous colonies were later recolonized. Six of these new colonies were genotyped; five were monogynous and one polygynous. Social structure shifts, queen replacement events, and colony extinctions occurred throughout our entire study area (Fig. S2).

\section{Polygynous colonies}

The annualized rate of social structure shift from polygyny to monogyny was $1.4 \%$. Two of the colonies that shifted from polygyny to monogyny appeared to be the result of a reduction in queen number where one of the original queens persisted alone, while two appeared to involve a queen replacement, based on pedigree analysis (Table 1, Fig. S4).

We also detected signs that queen number varied within colonies that remained polygynous (Fig. 1). In eight of these colonies, the relatedness among workers increased significantly over time, suggesting a reduction in queen number (average re- latedness \pm SE before shift: $r=0.03 \pm 0.05$, after shift: $r=0.3$ \pm 0.06 and between the two samples $r=0.08 \pm 0.05$ ). In five other polygynous colonies, the relatedness decreased, suggesting that new queens were adopted (average relatedness before shift: $r=0.25 \pm 0.06$, after shift: $r=-0.01 \pm 0.05$ and between the two samples $r=0.06 \pm 0.03$ ). Finally, two polygynous colonies showed signs of total queen replacement. The very low relatedness between the first and second samples indicates that the adopted queens were unrelated to the original queens in these colonies (Table 1).

The overall genetic turnover detected in polygynous colonies was $0.44 \pm 0.14$ across all resampling events. This value is consistent with regular queen replacement in polygynous colonies, and the confidence intervals broadly overlap with the genetic turnover estimates of monogynous colonies (Table 1). The genetic turnover was similar when colonies were resampled after 1 to 2 years $\left(N=26 ; Q_{\mathrm{e}}=0.47 \pm 0.22\right)$ or after 3 to 4 years $(N=52$; $\left.Q_{\mathrm{e}}=0.39 \pm 0.18\right)$. In colonies that were resampled after 5 years or more, the genetic turnover rate increased $\left(N=9 ; Q_{\mathrm{e}}=0.87 \pm\right.$ 0.44 ), indicating that most polygynous colonies experienced total or nearly total genetic turnover after 5 years or more. The genetic turnover corresponds to an effective queen replacement rate $(\tau)$ of 0.50 , which translates into an annualized estimate of $11.9 \%$. This result reflects queen replacement in an idealized situation where queens are as related as workers and reproduce equally, which is not always the case in other Formica species (Bargum and Sundström 2007). The queen replacement rate was not significantly different in polygynous and monogynous colonies (Fisher's exact test: $P=0.60$ ).

In total, 17 of 104 (16\%) marked polygynous colonies went extinct during our study period. The annualized colony extinction rate was $3.5 \%$. Two abandoned nest sites from polygynous colonies were later recolonized by polygynous groups. During our study period, monogynous colonies were significantly more likely to go extinct each year than polygynous ones (Fisher's exact test: $P=0.031$ ). As with the monogynous colonies, shifts in queen number and colony extinction were observed in polygynous colonies throughout our study area (Fig. S2).

\section{POPULATION DYNAMICS}

At the population level, we found that the average relatedness as well as the proportion of monogynous and polygynous colonies remained relatively stable during our 15 -year observation period (Table 2). Despite some minor annual fluctuations in the representation of each social form, this population does not appear to be on a course toward losing either social form.

In line with the apparent stability of the social polymorphism at the population level, mate number in monogynous colonies appeared stable over time. Across the 55 monogynous colonies sampled in 2009 to 2010 , the genetically effective mate number 
Table 2. Summary of the social structure at the population level in each sampling year. $95 \%$ confidence intervals are shown in square brackets.

\begin{tabular}{llllll}
\hline $\begin{array}{l}\text { Sampling } \\
\text { Year }\end{array}$ & $\begin{array}{l}\text { Nb of Colonies } \\
\text { Sampled }\end{array}$ & $\begin{array}{l}\text { Proportion } \\
\text { Monogynous }\end{array}$ & $\begin{array}{l}\text { Average Intracolony } \\
\text { Relatedness }\end{array}$ & $\begin{array}{l}\text { Nb of Colonies } \\
\text { Resampled }\end{array}$ & $\begin{array}{l}\text { Proportion } \\
\text { Monogynous }\end{array}$ \\
\hline 1996 & 25 & $0.48[0.28 ; 0.68]$ & $0.43[0.3 ; 0.56]$ & 0 & NA \\
2000 & 31 & $0.45[0.29 ; 0.64]$ & $0.43[0.32 ; 0.54]$ & 0 & NA \\
2001 & 103 & $0.65[0.56 ; 0.74]$ & $0.55[0.49 ; 0.6]$ & 24 & $0.42[0.21 ; 0.58]$ \\
2002 & 8 & $0.5[0.13 ; 0.88]$ & $0.36[0.17 ; 0.54]$ & 0 & NA \\
2005 & 70 & $0.56[0.44 ; 0.67]$ & $0.46[0.38 ; 0.53]$ & 65 & $0.58[0.45 ; 0.69]$ \\
2006 & 68 & $0.51[0.40 ; 0.63]$ & $0.43[0.36 ; 0.49]$ & 19 & $0.74[0.47 ; 0.84]$ \\
2007 & 24 & $0.79[0.63 ; 0.96]$ & $0.61[0.52 ; 0.69]$ & 4 & $0.5[0 ; 0.75]$ \\
2009 & 102 & $0.5[0.41 ; 0.59]$ & $0.51[0.45 ; 0.57]$ & 68 & $0.5[0.37 ; 0.6]$ \\
2010 & 22 & $0.25[0.08 ; 0.42]$ & $0.31[0.21 ; 0.43]$ & 11 & $0.27[0 ; 0.42]$ \\
\hline
\end{tabular}

was 1.08 , with $5.4 \%$ of the queens having mated with two males. These estimates are not significantly different from the ones obtained in the 71 monogynous colonies sampled in 2000 to 2001 (effective mate number of 1.04 and $10 \%$ of queens mated with two males, respectively; Fisher's exact test: $P=0.52$; Chapuisat et al. 2004). We did not detect evidence of queen remating in resampled colonies.

Queen number in polygynous colonies also seemed relatively constant at the population level. The effective queen number in polygynous colonies was not significantly different between 2000 and 2001 (4.3 or 5.3 for unrelated or related queens, respectively; Chapuisat et al. 2004) and 2009 and 2010 (3.9 or 4.8, respectively; Welch two-sample $t$-test: $t_{78.6}=1.1326, P=0.26$ ).

As in previous studies (Chapuisat et al. 2004), we did not find evidence of genetic differentiation between the two social forms at eight microsatellite loci (Table S1). However, because these loci cover only a tiny portion of the genome, this result does not rule out the possibility that genes in other parts of the genome are associated with social form.

\section{Discussion}

The dynamics of breeding groups play a central role in social evolution (Ross 2001; Bourke 2011). Here, we profit from our long-term genetic monitoring of a large number of ant colonies to investigate the dynamics of social structure variation over time, both within colonies and across the population. We found that Formica selysi colonies exhibit bidirectional shifts in social structure at an annual rate of about $2.3 \%$. Both monogynous and polygynous colonies also experience regular genetic turnover, with an annual effective queen replacement rate of about $10.3 \%$ and $11.9 \%$, respectively. At the population level, the proportion of monogynous and polygynous colonies remained similar across our 15-year observation period.

A degree of lability in social structure is consistent with previous experiments that showed that $F$. selysi queens from both social forms can establish colonies either independently or in associations (Reber et al. 2010) and that colonies of both social forms tend to reject unrelated queens, but will often accept nestmate queens (Meunier et al. 2011). However, cross-fostering experiments revealed that size differences between monogynous and polygynous queens, as well as the development time and growth rate of worker brood, matched their social origin, rather than their fostered environment (Meunier and Chapuisat 2009; Purcell and Chapuisat 2012). This suggests that some as yet unknown genetic, epigenetic, or maternal effect also contributes to the differences between the social forms. Taken together, our findings indicate that $F$. selysi shows a higher degree of flexibility than the red fire ant $S$. invicta, where the social form appears to be under strict genetic control (Ross and Keller 1998; Krieger and Ross 2002; Ross and Keller 2002). Overall, the relative lability in social structure over years, combined with previous experimental and field studies, suggests that the mechanism leading to social polymorphism in $F$. selysi likely falls at an intermediate position along the spectrum between genetic control and phenotypic plasticity in response to environmental cues.

We do not yet know the mechanisms that dictate when a colony shifts in social structure, but there are several possibilities. For example, queen number may be adjusted in response to environmental or population density conditions on the one hand or to the age or reproductive status of the mother queen(s) on the other hand. The bidirectional shifts in social structure occurred in colonies distributed throughout our study area (Fig. S2), so it is not obvious which environmental cues, if any, trigger these changes. These results contrast with studies in which queen number varied predictably along ecological or temporal gradients (Pedersen and Boomsma 1999; Ingram 2002; Buczkowski 2010). Intrinsic properties of the colonies could also trigger a change in social structure. For example, workers in monogynous colonies headed by an old queen may be increasingly likely to accept a new queen (particularly a relative) if their own queen is producing fewer 
viable eggs (Al-Lawati and Bienefeld 2009). In the past, we have detected a few colonies that were headed by two or three related queens, but otherwise exhibited properties of monogynous colonies (Schwander et al. 2005), which would be consistent with this hypothesis. Declining monogynous and polygynous colonies might also be increasingly susceptible to an invasion by foreign queens.

Queen replacement events were relatively common in colonies, both monogynous and polygynous, that did not shift in social structure. In monogynous colonies, we found evidence of queen replacement through pedigree analysis in about $20 \%$ of our resampling efforts, for an annual estimate of $6.4 \%$. The estimate of effective queen replacement $(\tau)$ based on relatedness in monogynous colonies was somewhat higher at $33 \%$ across all resampling events, for an annual estimate of $10.3 \%$. This value was surprisingly similar to our estimate of $50 \%$ effective queen replacement $(\tau)$ across resampling events in polygynous colonies, which gave an annualized estimate of $11.9 \%$. These estimates are likely to be conservative because we may have missed queen replacement events within our longer sampling intervals; in the latter case, the estimate may be particularly conservative because replacement of queens by related queens may pass undetected when queen number is high. In contrast with our findings, other species generally exhibit a higher rate of queen replacement in polygynous than in monogynous colonies (e.g., Pedersen and Boomsma 1999; Bargum et al. 2007). In addition, in polygynous colonies of our study population, decreases in queen number tended to be more common than increases (Fig. S4), suggesting that polygynous colonies might be less prone to accept new queens than would be expected based on observations in highly polygynous species (e.g., Pedersen and Boomsma 1999; Ingram 2002).

Overall, colony inheritance or colony take over by young queens played a major role in both social forms in our study population, in line with studies in other social insects and social vertebrates (Clutton-Brock 2002; Cant et al. 2006; Leadbeater et al. 2011). The adopted queens were sometimes related to the original queen(s), but sometimes were unrelated to previous colony members. For example, monogynous colonies seemed to be passed to daughter queens in about two thirds of the queen replacement events. Thus, a surprising number of colonies may have been passed to nonrelatives. Frequent replacement of reproductive individuals by less related individuals is further supported by the high rates of effective genetic turnover across all resamples, which reached $25 \%$ and $44 \%$ in monogynous and polygynous colonies, respectively (Table 1). Moreover, the effective genetic turnover was still high when considering only resamples spanning 1 to 2 years ( $21 \%$ and $47 \%$ for monogynous and polygynous colonies, respectively).

Using all of the marked colonies in our study area, we estimated the colony extinction rate to be $5.7 \%$ and $3.5 \%$ per year for monogynous and polygynous colonies, respectively, which corresponds to estimates of colony lifespan of approximately 18 and 28 years. F. selysi colonies may survive for decades, potentially through continual replacement of aging queens. These estimates apply only to colonies that did not shift in social structure; we do not yet know how social structure shifts will affect colony longevity.

Our survey revealed that the breeding structure of individual colonies was dynamic, with shifts in social structure, adoption of related or unrelated queens, and replacement of original queens. We detected more variation than in our previous study, particularly with respect to effective genetic turnover and queen replacement, which we had previously estimated with a snapshot comparison of the genotypes of adult workers to brood (Chapuisat et al. 2004). This difference shows the importance of performing a long-term survey on a large number of social groups to have enough power to detect rare events (Ross 2001). A high turnover of queens and occasional acceptance of unrelated queens was expected in polygynous colonies, as it has been documented in many other polygynous species (e.g., Crozier and Pamilo 1996; Evans 1996; Chapuisat and Keller 1999; Pedersen and Boomsma 1999; Heinze and Keller 2000; Holzer et al. 2008). The finding of colony inheritance by related queens or colony takeover by unrelated queens in monogynous colonies is more surprising, as monogynous colonies of ants have generally been found to be highly stable (e.g., Pamilo 1991b; Crozier and Pamilo 1996). Overall, our results highlight the great diversity of reproductive strategies exhibited by social insects (Heinze and Keller 2000). In particular, joining unrelated colonies or taking over queenless nests appear to be viable options for young queens, in addition to staying in the maternal nest (Meunier et al. 2011) or founding a new colony independently (Reber et al. 2010).

In spite of the flexibility of queen number at the colony level, the overall proportion of monogynous and polygynous colonies at the population level remained relatively stable over the 15 years of our survey. We did observe some small variation in average intracolony relatedness across years, but this variation might be in part due to sampling bias. We did not sample equally in all patches every year, which could influence the proportion of each social form due to their spatially autocorrelated distribution (Fig. S2). There was no sign of cyclical variation in colony queen number, either at the colony level (Brown and Keller 2002; Brown et al. 2002) or at the population level (Elmes and Petal 1990). More importantly, we found no evidence that the effective number of queens increased in our population. Hence, our data do not support the hypothesis that polygyny increases with population age due to habitat saturation (Seppä et al. 1995; see also Hannonen et al. 2004).

The finding that neither social form became competitively dominant and increased within a time-frame of 15 years raises 
the question: what factors maintain the polymorphism in social structure at the population level? Some form of balancing selection might be involved, which could be mediated by microhabitat heterogeneity, environmental instability, or variation in parasite pressure, for example. Even if the social forms appeared stable at the population level during our study, however, the relative representation of each social form might still vary over longer time periods or if the ecological conditions change.

Importantly, we found no genetic differentiation between the monogynous and polygynous social forms when controlling for the unequal representation of social forms in genetically differentiated patches (Table S1). This result is consistent with the one from 2000 to 2001 (Chapuisat et al. 2004), and suggests that gene flow between social forms is maintained. The shifts in social structure documented in our survey might contribute to gene flow between social forms. Mating between social forms, adoptions of foreign queens and flexibility in the mode of colony founding by young queens originating from each social structure are further ways to maintain gene flow between social forms (this study; Chapuisat et al. 2004; Reber et al. 2010; Meunier et al. 2011). The gene flow and absence of differentiation at eight microsatellite loci does not, however, rule out the possibility that some genetic element unlinked to these markers influences the colony social structure, as in fire ants (Ross and Keller 1998; Krieger and Ross 2002).

Overall, our findings indicate that colony queen number is a somewhat flexible trait in F. selysi. Such flexibility suggests that queen number is, at least partially, a phenotypically plastic trait. Our results also indicate that colonies may be able to adjust the number of queens during the lifetime of the original queen(s), which raises questions about whether social insects change their breeding system in response to any particular environmental or phenological cues. More broadly, gaining insight into the factors favoring either simple families or more complex social groups will help us to understand the selective forces maintaining variation in social systems.

\section{ACKNOWLEDGMENTS}

We thank the many students and collaborators who participated to the monitoring, sampling, and genotyping of ants: Marie Ballif, Dominique Bays, Samuel Bocherens, Christian Bernasconi, Grégoire Castella, Sophie Cotting, Daniel Croll, Loïc Degen, Joël Meunier, Corinne Peter, Anabelle Reber, Hervé Rosset, Tanja Schwander, and Charlotte Trippi. We also thank Alan Brelsford, Timothée Brütsch, Liselotte Sundström, and two anonymous reviewers for their comments on the article. This study was supported by grants 31003A_125306, 31003A-108263, and 3100-061934 from the Swiss National Science Foundation.

\section{LITERATURE CITED}

Al-Lawati, H., and K. Bienefeld. 2009. Maternal age effects on embryo mortality and juvenile development of offspring in the honey bee (Hymenoptera: Apidae). Ann. Entomol. Soc. Am. 102:881-888.
Balloux, F., J. Goudet, and N. Perrin. 1998. Breeding system and genetic variance in the monogamous, semi-social shrew, Crocidura russula. Evolution 52:1230-1235.

Bargum, K., H. Helanterä, and L. Sundström. 2007. Genetic population structure, queen supersedure and social polymorphism in a social Hymenoptera. J. Evol. Biol. 20:1351-1360.

Bargum, K., and L. Sundström. 2007. Multiple breeders, breeder shifts and inclusive fitness returns in an ant. Proc. R. Soc. B 274:1547-1551.

Boomsma, J. J. 2007. Kin selection versus sexual selection: why the ends do not meet. Curr. Biol. 17:R673-R683.

Boomsma, J. J., and F. L. W. Ratnieks. 1996. Paternity in eusocial hymenoptera. Phil.Trans. R. Soc. B 351:947-975.

Bourke, A. F. G. 2011. Principles of social evolution. Oxford Univ. Press, Oxford, U. K.

Bourke, A. F. G., and N. R. Franks. 1995. Social evolution in ants. Princeton Univ. Press, Princeton, NJ.

Brown, W. D., and L. Keller. 2002. Queen recruitment and split sex ratios in polygynous colonies of the ant Formica exsecta. Ecol. Lett. 5: 102-109.

Brown, W. D., L. Keller, and L. Sundström. 2002. Sex allocation in moundbuilding ants: the roles of resources and queen replenishment. Ecology 83:1945-1952.

Buczkowski, G. 2010. Extreme life history plasticity and the evolution of invasive characteristics in a native ant. Biol. Invasions 12:33433349.

Cant, M. A., J. B. Llop, and J. Field. 2006. Individual variation in social aggression and the probability of inheritance: theory and a field test. Am. Nat. 167:837-852.

Chapuisat, M. 1996. Characterization of microsatellite loci in Formica lugubris $B$ and their variability in other ant species. Mol. Ecol. 5:599601.

2. 1998. Mating frequency of ant queens with alternative dispersal strategies, as revealed by microsatellite analysis of sperm. Mol. Ecol. 7:1097-1105.

Chapuisat, M., S. Bocherens, and H. Rosset. 2004. Variable queen number in ant colonies: no impact on queen turnover, inbreeding, and population genetic differentiation in the ant Formica selysi. Evolution 58:10641072 .

Chapuisat, M., J. Goudet, and L. Keller. 1997. Microsatellites reveal high population viscosity and limited dispersal in the ant Formica paralugubris. Evolution 51:475-482.

Chapuisat, M., and L. Keller. 1999. Extended family structure in the ant Formica paralugubris: the role of the breeding system. Behav. Ecol. Sociobiol. 46:405-412.

Clutton-Brock, T. 2002. Breeding together: kin selection and mutualism in cooperative vertebrates. Science 296:69-72.

Crozier, R. H., and P. Pamilo. 1996. Evolution of social insect colonies: sex allocation and kin selection. Oxford Univ. Press, Oxford, U. K.

DeHeer, C. J., and J. M. Herbers. 2004. Population genetics of the socially polymorphic ant Formica podzolica. Ins. Soc. 51:309-316.

Elmes, G. W. 1987. Temporal variation in colony populations of the ant Myrmica sulcinodis. 1. Changes in queen number, worker number and spring production. J. Anim. Ecol. 56:559-571.

Elmes, G. W., and J. Petal. 1990. Queen number as an adaptable traitevidence from wild populations of 2 red ant species (Genus Myrmica). J. Anim. Ecol. 59:675-690.

Evans, J. D. 1996. Queen longevity, queen adoption, and posthumous indirect fitness in the facultatively polygynous ant Myrmica tahoensis. Behav. Ecol. Sociobiol. 39:275-284.

Field, J., R. J. Paxton, A. Soro, and C. Bridge. 2010. Cryptic plasticity underlies a major evolutionary transition. Curr. Biol. 20:2028-2031. 
Goropashnaya, A. V., P. Seppä, and P. Pamilo. 2001. Social and genetic characteristics of geographically isolated populations in the ant Formica cinerea. Mol. Ecol. 10:2807-2818.

Gyllenstrand, N., P. Seppä, and P. Pamilo. 2005. Restricted gene flow between two social forms in the ant Formica truncorum. J. Evol. Biol. 18:978984.

Hannonen, M., H. Helantera, and L. Sundstrom. 2004. Habitat age, breeding system and kinship in the ant Formica fusca. Mol. Ecol. 13:15791588 .

Heinze, J., and L. Keller. 2000. Alternative reproductive strategies: a queen perspective in ants. Trends Ecol. Evol. 15:508-512.

Heinze, J., N. Lipski, K. Schlehmeyer, and B. Hölldobler. 1995. Colony structure and reproduction in the ant, Leptothorax acervorum. Behav. Ecol. 6:359-367.

Herbers, J. M. 1986. Nest site limitation and facultative polygyny in the ant Leptothorax longispinosus. Behav. Ecol. Sociobiol. 19:115-122.

Herbers, J. M. 1993. Ecological determinants of queen number in ants. Pp. 262-293 in L. Keller, ed. Queen number and sociality in insects. Oxford Univ. Press, Oxford, U. K.

Hölldobler, B., and E. O. Wilson. 1977. The number of queens: an important trait in ant evolution. Naturwissenschaften 64:8-15.

Holzer, B., J. Meunier, L. Keller, and M. Chapuisat. 2008. Stay or drift? Queen acceptance in the ant Formica paralugubris. Ins. Soc. 55:392-396

Hughes, W. O. H., B. P. Oldroyd, M. Beekman, and F. L. W. Ratnieks. 2008a. Ancestral monogamy shows kin selection is key to the evolution of eusociality. Science 320:1213-1216.

Hughes, W. O. H., F. L. W. Ratnieks, and B. P. Oldroyd. 2008b. Multiple paternity or multiple queens: two routes to greater intracolonial genetic diversity in the eusocial Hymenoptera. J. Evol. Biol. 21:10901095.

Ingram, K. K. 2002. Plasticity in queen number and social structure in the invasive Argentine ant (Linepithema humile). Evolution 56:20082016.

Kautz, S., S. U. Pauls, D. J. Ballhorn, H. T. Lumbsch, and M. Heil. 2009. Polygynous supercolonies of the acacia-ant Pseudomyrmex peperi, an inferior colony founder. Mol. Ecol. 18:5180-5194.

Keller, L. 1995a. Parasites, worker polymorphism, and queen number in social insects. Am. Nat. 145:842-847.

. 1995b. Social life: the paradox of multiple-queen colonies. Trends Ecol. Evol. 10:355-360.

- 1998. Queen lifespan and colony characteristics in ants and termites. Ins. Soc. 45:235-246.

Keller, L., and M. Genoud. 1997. Extraordinary lifespans in ants: a test of evolutionary theories of ageing. Nature 389:958-960.

Keller, L., and L. Passera. 1989. Size and fat content of gynes in relation to the mode of colony founding in ants (Hymenoptera; Formicidae). Oecologia 80:236-240.

Krieger, M. J. B., and K. G. Ross. 2002. Identification of a major gene regulating complex social behavior. Science 295:328-332.

Leadbeater, E., J. M. Carruthers, J. P. Green, N. S. Rosser, and J. Field. 2011. Nest inheritance is the missing source of direct fitness in a primitively eusocial insect. Science 333:874-876.

Meunier, J., and M. Chapuisat. 2009. The determinants of queen size in a socially polymorphic ant. J. Evol. Biol. 22:1906-1913.

Meunier, J., L. Delaplace, and M. Chapuisat. 2010. Reproductive conflicts and egg discrimination in a socially polymorphic ant. Behav. Ecol. Sociobiol. 64:1655-1663.

Meunier, J., A. Reber, and M. Chapuisat. 2011. Queen acceptance in a socially polymorphic ant. Anim. Behav. 81:163-168.

Nonacs, P. 1988. Queen number in colonies of social Hymenoptera as a kinselected adaptation. Evolution 42:566-580.
Ost, M., B. D. Smith, and M. Kilpi. 2008. Social and maternal factors affecting duckling survival in eiders Somateria mollissima. J. Anim. Ecol. 77:315325 .

Pamilo, P. 1991a. Evolution of colony characteristics in social insects. II. Number of reproductive individuals. Am. Nat. 138:412-433.

. 1991b. Life span of queens in the ant Formica exsecta. Ins. Soc. 38:111-119.

Pedersen, J. S., and J. J. Boomsma. 1999. Effect of habitat saturation on the number and turnover of queens in the polygynous ant, Myrmica sulcinodis. J. Evol. Biol. 12:903-917.

Pompanon, F., A. Bonin, and P. Taberlet. 2005. Genotyping errors: causes, consequences and solutions. Nature 6:847-859.

Purcell, J. 2011. Geographic patterns in the distribution of social systems in terrestrial arthropods. Biol. Rev. 86:475-491.

Purcell, J., T. Brütsch, and M. Chapuisat. 2012. Effects of the social environment on the survival and fungal resistance of ant brood. Behav. Ecol. Sociobiol. 66:467-474.

Purcell, J., and M. Chapuisat. 2012. The influence of social structure on brood survival and development in a socially polymorphic ant: insights from a cross-fostering experiment. J. Evol. Biol. 25:2288-2297.

Queller, D. C., and K. F. Goodnight. 1989. Estimating relatedness using genetic markers. Evolution 242:258-275.

Reber, A., G. Castella, P. Christe, and M. Chapuisat. 2008. Experimentally increased group diversity improves disease resistance in an ant species. Ecol. Lett. 11:682-689.

Reber, A., J. Meunier, and M. Chapuisat. 2010. Flexible colony-founding strategies in a socially polymorphic ant. Anim. Behav. 79:467472.

Reber, A., J. Purcell, S. D. Buechel, P. Buri, and M. Chapuisat. 2011. The expression and impact of antifungal grooming in ants. J. Evol. Biol. 24:954-964.

Ross, K. G. 1993. The breeding system of the fire ant Solenopsis invicta: effects on colony genetic structure. Am. Nat. 141:554-576.

. 2001. Molecular ecology of social behaviour: analyses of breeding systems and genetic structure. Mol. Ecol. 10:265-284.

Ross, K. G., and L. Keller. 1998. Genetic control of social organization in an ant. Proc. Natl. Acad. Sci. USA 95:14232-14237.

- 2002. Experimental conversion of colony social organization by manipulation of worker genotype composition in fire ants (Solenopsis invicta). Behav. Ecol. Sociobiol. 51:287-295.

Rosset, H., and M. Chapuisat. 2006. Sex allocation conflict in ants: when the queen rules. Curr. Biol. 16:328-331.

. 2007. Alternative life-histories in a socially polymorphic ant. Evol. Ecol. 21:577-588.

Schlick-Steiner, B. C., F. M. Steiner, M. Sanetra, B. Seifert, E. Christian, and C. Stauffer. 2007. Lineage specific evolution of an alternative social strategy in Tetramorium ants (Hymenoptera : Formicidae). Biol. J. Linn. Soc. 91:247-255.

Schmid-Hempel, P., and R. H. Crozier. 1999. Polyandry versus polygyny versus parasites. Phil. Trans. R. Soc. B 354:507-515.

Schwander, T., H. Rosset, and M. Chapuisat. 2005. Division of labour and worker size polymorphism in ant colonies: the impact of social and genetic factors. Behav. Ecol. Sociobiol. 59:215-221.

Seppä, P., M. Gyllenstrand, J. Corander, and P. Pamilo. 2004. Coexistence of the social types: genetic population structure in the ant Formica exsecta. Evolution 58:2462-2471.

Seppä, P., L. Sundström, and P. Punttila. 1995. Facultative polygyny and habitat succession in boreal ants. Biol. J. Linn. Soc. 56:533-551.

Shoemaker, D. D., and K. G. Ross. 1996. Effects of social organization on gene flow in the fire ant Solenopsis invicta. Nature 383:613616. 
Sommer, S., D. Schwab, and J. U. Ganzhorn. 2002. MHC diversity of endemic Malagasy rodents in relation to geographic range and social system. Behav. Ecol. Sociobiol. 51:214-221.

Wang, J. 2011. COANCESTRY: a program for simulating, estimating and analysing relatedness and inbreeding coefficients. Mol. Ecol. Res. 11:141-145
Wang, J., and A. W. Santure. 2009. Parentage and sibship inference from multilocus genotype data under polygamy. Genetics 181:1579-1594.

Wang, J. 2004. Sibship reconstruction from genetic data with typing errors. Genetics 166:1963-1979.

Associate Editor: L. Sundström

\section{Supporting Information}

Additional Supporting Information may be found in the online version of this article at the publisher's website:

Figure S1. Flow chart showing the number of colonies that were initially sampled (white boxes) and resampled (grey boxes) in each sampling period (1996, 2000-2002, 2005-2007, and 2009-2010, x-axis).

Figure S2. Map showing the distribution of colonies in our focal population along the Rhône River in Valais, Switzerland.

Figure S3. The distribution of intracolony relatedness estimates in 2009 to 2010.

Figure S4. Intracolony relatedness comparisons.

Table S1. Three-level hierarchical $F$-analysis of variance in which individuals were nested within colonies, colonies within patches, and patches within the full population, using the genotypes from 2009 to 2010 ( $N=117$ colonies). 